Check for updates

Cite this: RSC Adv., 2018, 8, 4295

Received 27th November 2017 Accepted 16th January 2018

DOI: $10.1039 / c 7 r a 12812 f$

rsc.li/rsc-advances

\section{Can water continuously oxidize the PuO molecule? Mechanisms, topological analysis and rate constant calculations $\dagger$}

\begin{abstract}
Wenxia Niu, ${ }^{\mathrm{a}}$ Feng Xie, (D) ${ }^{\mathrm{b}}$ Peng Li, (D) ${ }^{* c}$ Jie Ma, ${ }^{\mathrm{c}}$ Tao Gao ${ }^{\mathrm{d}}$ and Huaqiang Yin ${ }^{\mathrm{b}}$
A detailed description of the reaction mechanisms provides insights into the PuO continuously oxidized by water in the gas-phase. Two reaction pathways were located, isomerization and dehydrogenation, and the corresponding different products are closely examined. Our results indicated that it is difficult to oxidize $\mathrm{PuO}$ with a water molecule at room temperature. In the early stages of reaction, the reaction rate constants of the first $\mathrm{O}-\mathrm{H}$ bond dissociation are very small. Once the dissociations of the $\mathrm{O}-\mathrm{H}$ bonds were complete, the remaining process will be exothermic, and the best thermochemical conditions observed at dehydrogenation around $42.3 \mathrm{kcal} \mathrm{mol}^{-1}$. Minimum energy crossing points between the septuplet-quintet and septuplet-triplet PESs were searched. Electron localization function and atoms in molecules were performed to analyze the topological property of bonding evolution along the reactions. Rate constants were calculated between 298 and $1000 \mathrm{~K}$ by using variational transition-state theory including one-dimensional tunneling effects.
\end{abstract}

\section{Introduction}

Plutonium, which in some forms is used in most of the nuclear industry, has unique chemical and physical properties as well as strong chemical reactivity. When exposed to moisture and atmospheric components, the metal surface readily corrodes. ${ }^{1}$ An in-depth understanding of the corrosion mechanism is an important basis for seeking effective plutonium surface corrosion resistance methods. Besides, exploring the most stable plutonium oxide and whether plutonium oxide further oxidizes are also important issues in plutonium science. ${ }^{2,3}$ Therefore, over the last few decades, the reaction of plutonium with small molecules in the gas phase has attracted significant attention both in experimental ${ }^{1-12}$ and theoretical studies..$^{13-21}$ In addition, the reaction of plutonium with water which can provide some insight into the corrosive mechanism of steam on nuclear fuel is a more imperative and challenging research field.

In terms of experimental study, $\mathrm{PuO}_{2}$ solid reacts with water vapor to form $\mathrm{PuO}_{2+x}$, which was detected and characterized by

${ }^{a}$ Department of Physics, Taiyuan Normal University, Taiyuan, 030031, China ${ }^{b}$ Institute of Nuclear and New Energy Technology, Collaborative Innovation Center of Advanced Nuclear Energy Technology, Key Laboratory of Advanced Reactor Engineering and Safety of Ministry of Education, Tsinghua University, Beijing 100084, China

'School of Physics and Electronic Engineering, Shanxi University, Taiyuan, 030006, China.E-mail: lip@sxu.edu.cn

${ }^{d}$ Institute of Atomic and Molecular Physics, Sichuan University, Chengdu, 610065, China

† Electronic supplementary information (ESI) available. See DOI: 10.1039/c7ra12812f mass spectrometric (MS) analysis. ${ }^{2,8}$ These studies yielded an extremely important insight, that $\mathrm{PuO}_{2+x}$ is the stable oxides of plutonium, and $\mathrm{H}_{2}$ formed during the $\mathrm{Pu}+\mathrm{H}_{2} \mathrm{O}$ reaction will continue to participate in the reaction and produce plutonium hydroxide PuOH. In a recent experimental study, the gas phase monopositive plutonyl ion $\mathrm{PuO}_{2}^{+}$reaction with water was investigated by employing electrospray ionization (ESI) mass spectrometry. ${ }^{10}$ The spectra of products $\mathrm{PuO}_{2}(\mathrm{OH})^{+}$, $\mathrm{PuO}_{2}^{+}\left(\mathrm{H}_{2} \mathrm{O}\right)_{4}$ and $\mathrm{PuO}_{2}^{+}\left(\mathrm{O}_{2}\right)\left(\mathrm{H}_{2} \mathrm{O}\right)_{3}$ were detected. Because of the experimental specificity of PuO, there is no report of PuO being continuously oxidized by $\mathrm{H}_{2} \mathrm{O}$ in the experiment.

Undoubtedly, experimental investigations provide precious original information of the gas phase plutonium reacted with water. However, limitations still exist, and no direct structural and detailed mechanism information was obtained. On one hand, the potentially dangerous of plutonium brings difficulties and risks to the experimental study. On the other hand, the development and application of surface anti-corrosion experimental techniques require basic research provide detailed and in-depth understanding of the microscopic mechanism. As a crucial complement of experimental researches, these detailed information can reliably computed by density functional theory (DFT), and these theory methods have been successful used in the study of actinide corrosive reaction..$^{22-27}$ In 2015 and 2017, $\mathrm{Ao}^{28,29}$ reported the existence of PuO and the formation of hyperstoichiometric $\mathrm{PuO}_{2}$ from first principle calculation. There results indicated that PuO is thermodynamically unstable at ambient pressure.

In our recent theoretical study, ${ }^{21}$ the mechanisms and molecular dynamics of the reaction of gas phase Pu atom with 
$\mathrm{H}_{2} \mathrm{O}$ were investigated by DFT computation. The reaction pathways shown in the following equations were determined.

$$
\begin{gathered}
\mathrm{Pu}+\mathrm{H}_{2} \mathrm{O} \rightarrow \mathrm{HPuOH} \rightarrow \mathrm{PuO}+\mathrm{H}_{2} \\
\mathrm{Pu}+\mathrm{H}_{2} \mathrm{O} \rightarrow \mathrm{HPuOH} \rightarrow \mathrm{OPuH}_{2}
\end{gathered}
$$

The $\mathrm{PuO}+\mathrm{H}_{2}$ process was found as the minimum energy reaction channel of $\mathrm{Pu}+\mathrm{H}_{2} \mathrm{O}$ reaction, with heat liberation around $36.7 \mathrm{kcal} \mathrm{mol}^{-1}$. Our previous theoretical studies have demonstrated that such reactions are usually as two-state reactivity, which means there are intersystem crossing between the potential surfaces of different spin multiplicity. ${ }^{26,27}$

In the work, we perform the DFT calculations combined with variational transition state theory, focusing on the investigation of detailed mechanism, topological properties and rate constants of gas phase $\mathrm{PuO}$ react with $\mathrm{H}_{2} \mathrm{O}$ molecules. From the electronic structure level, the microscopic mechanism of plutonium corrosion can be reasonably evaluated, and a reliable theoretical basis for the interpretation of the practical corrosions of plutonium will be provided.

\section{Computational details}

Different levels of methods were employed to optimize the geometries and locate transition states on the potential energy surface of the possible spin states. The B3LYP, ${ }^{\mathbf{3 0 , 3 1}}$ B3PW91, ${ }^{32}$ PBE0 (ref. 33) and PW91PW91 (ref. 34) functions were used together with the Stuttgart-Dresden-Bonn relativistic effective core potential (SDD-RECP) ${ }^{35}$ for the $\mathrm{Pu}$ atom. The Pople type basis set $6-311++\mathrm{G}(\mathrm{d}, \mathrm{p})$ was adopted for $\mathrm{O}$ and $\mathrm{H}$ atoms. ${ }^{36}$ These calculations were implemented in the Gaussian 03 package. ${ }^{37}$ The located transition states on each potential energy surface have examined by intrinsic reaction coordinate (IRC) calculation, and the corresponding imaginary frequency connect the reactants and products correctly. The reported relative energies include the vibrational zero point energy (VZPE) corrections. This set of research methods has been successfully implemented in previous study on corrosion reaction of actinide systems. The minimum energy crossing point (MECP) between different spin potential surfaces of was identified using the program of sobMECP program ${ }^{38,39}$ and Gaussian 03 .

In order to get more in-depth bonding characteristic information along the pathway, the topological analysis including

Table 1 Comparison of observed values and calculated harmonic

\begin{tabular}{|c|c|c|c|c|c|}
\hline & $\mathrm{PuO}$ & $\mathrm{PuO}_{2}$ & & & \\
\hline & $\nu \Sigma$ & $\nu \Sigma_{\mathrm{u}}$ & $\nu \Sigma_{\mathrm{g}}$ & $\nu \Pi$ & $\nu \Pi$ \\
\hline $\mathrm{B}^{2} \mathrm{LYP}^{a}$ & 792.729 & 808.416 & 757.008 & 160.118 & 160.114 \\
\hline B3PW91 $^{a}$ & 814.975 & 833.031 & 778.240 & 170.327 & 170.319 \\
\hline $\mathrm{PBE}^{a}$ & 816.413 & 844.909 & 789.743 & 173.530 & 173.523 \\
\hline $\mathrm{PW}^{a}{ }^{a}$ & 768.923 & 823.566 & 709.600 & 173.611 & 173.606 \\
\hline Exper. $^{b}$ & 822.28 & 794.25 & & & \\
\hline
\end{tabular}
frequencies $\left(\mathrm{cm}^{-1}\right)$ for $\mathrm{PuO}$ and $\mathrm{PuO}_{2}$ molecule electron localization function (ELF) ${ }^{\mathbf{4 0 , 4 1}}$ and atoms-in-molecules $(\mathrm{AIM})^{\mathbf{4 2}}$ as well as Mayer bond order ${ }^{\mathbf{4 3}}$ were performed. The topological properties of the $(3,-1)$ bond critical points (BCP) in the gradient field of the electron density were obtained. These analysis were performed with the Multiwfn package. ${ }^{\mathbf{4 4}}$

Rate constants are calculated between 298 and $1000 \mathrm{~K}$ by using variational transition state (VTST) theory ${ }^{45}$ including onedimensional tunneling effects (Wigner ${ }^{46}$ and Eckart ${ }^{47}$ ). All rate constant computations were carried out by using the KiSThelP program. ${ }^{48}$
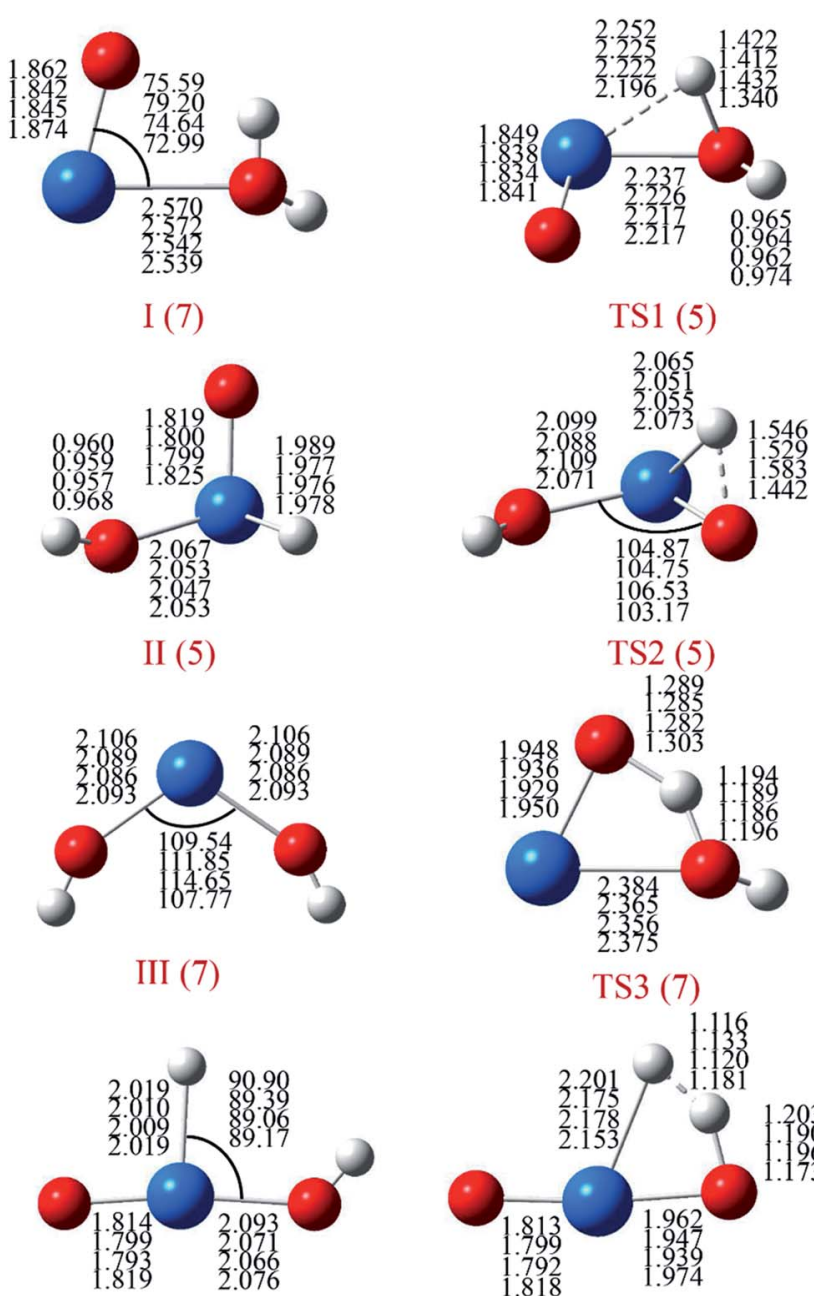

IV (5)

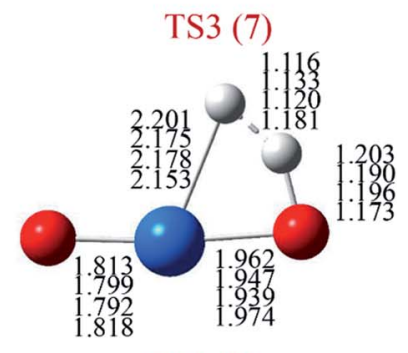

TS4 (5)
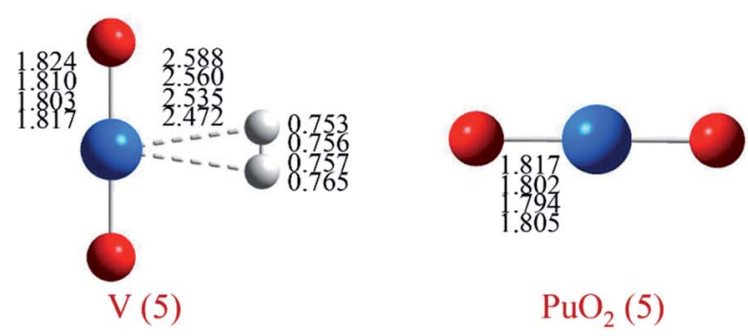

Fig. 1 Structures and selected geometric parameters of stationary points on the $\mathrm{PuO}+\mathrm{H}_{2} \mathrm{O}$ potential energy surface optimized at the B3LYP/SDD, B3PW91/SDD, PBE0/SDD and PW91/SDD levels of theory (from top to bottom rows, respectively). Bond distances are in $\AA$, and angles are in degrees. 


\section{Results and discussion}

Although current computational methods have been successfully performed in the previous studies, we still verify the correctness of these methods in the plutonium oxide system. We calculated the vibrational frequencies of the $\mathrm{PuO}$ and $\mathrm{PuO}_{2}$ complexes and compared with the available experimental data, of which the results are collated in Table 1 . As can be seen, the results from method schemes we adopted are in most cases closer to the available experimentally detected data.

\section{Structures and energetics}

For each species on the different spin potential surfaces, several initial geometries were constructed, and optimized by full geometry without symmetry constrain at different levels of theory. Triplet, quintet, and septuplet spin states were taken into account. Geometric parameters of the lowest energy spin states for stationary species are presented in Fig. 1 . It can be seen that the geometric parameters are relatively less dependence on the method, most bond lengths are within $0.05 \AA$ of the difference. These angles agree to $\pm 5^{\circ}$, except for the $\mathrm{O}-\mathrm{Pu}-\mathrm{O}$ bond of complex III.

The potential energy profiles of $\mathrm{PuO}+\mathrm{H}_{2} \mathrm{O}$ reactions are reported in Fig. 2 and 3, the corresponding relative energies are regarding the reactants' ground state asymptotes.

We have found that the $\mathrm{PuO}+\mathrm{H}_{2} \mathrm{O}$ has similar mechanisms with the insertion reaction for actinide atoms in our previous studies from an overall perspective. ${ }^{17,21,26}$ Two reaction channels were found, isomerization and hydrogen elimination, and the formation of $\mathrm{PuO}_{2}+\mathrm{H}_{2}$ is more thermodynamically favorable.

The reaction of $\mathrm{PuO}+\mathrm{H}_{2} \mathrm{O}$ starts with the formation of the initial complex, $\mathrm{OPu}-\mathrm{OH}_{2}(\mathbf{I})$, exothermic by as much as

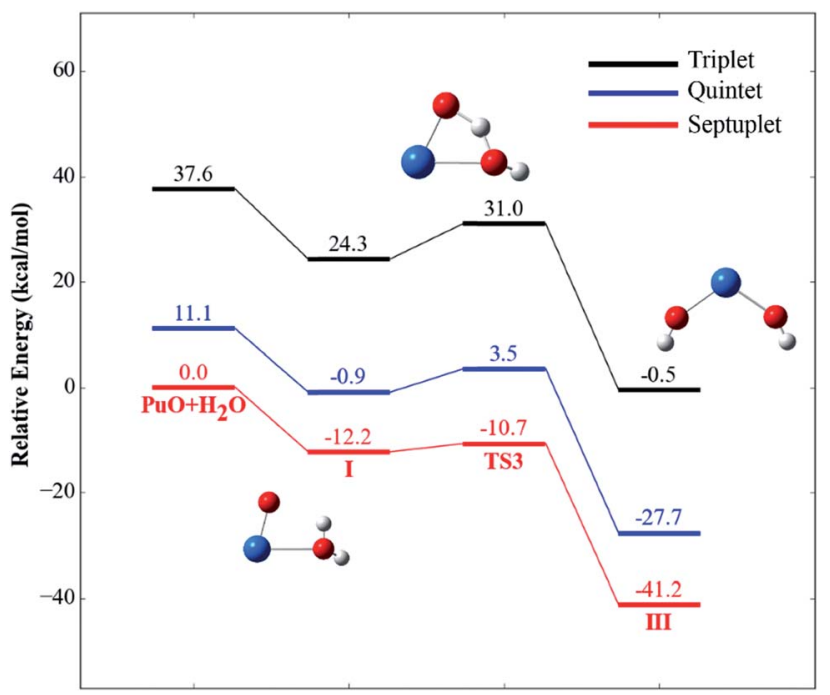

Fig. 3 Potential energy profiles for the reaction of $\mathrm{PuO}+\mathrm{H}_{2} \mathrm{O}$ (path $\mathrm{B}$ ) at the PW91/SDD levels of theory.

$-12.2 \mathrm{kcal} \mathrm{mol}^{-1}$ at ground state septuplet spin state. Hereafter, the first $\mathrm{O}-\mathrm{H}$ bond of water was activated, and the corresponding $\mathrm{H}$ atom will shift from $\mathrm{O}$ atom of water to $\mathrm{PuO}$ section. Our results show that there are two possible directions for this shift, one is perpendicular to the molecular plane and the $\mathrm{H}$ atom trapped by $\mathrm{Pu}$ atom; the other is in the molecular plane and the $\mathrm{H}$ atom trapped by $\mathrm{O}$ atom of PuO. Therefore, the reaction system overcomes two different transition states (TS1 and TS3) after complex I. For the sake of discussion, the TS1 path is named path A, and TS3 path is named path B, the corresponding potential energy profiles are plotted in Fig. 2 and 3, respectively.

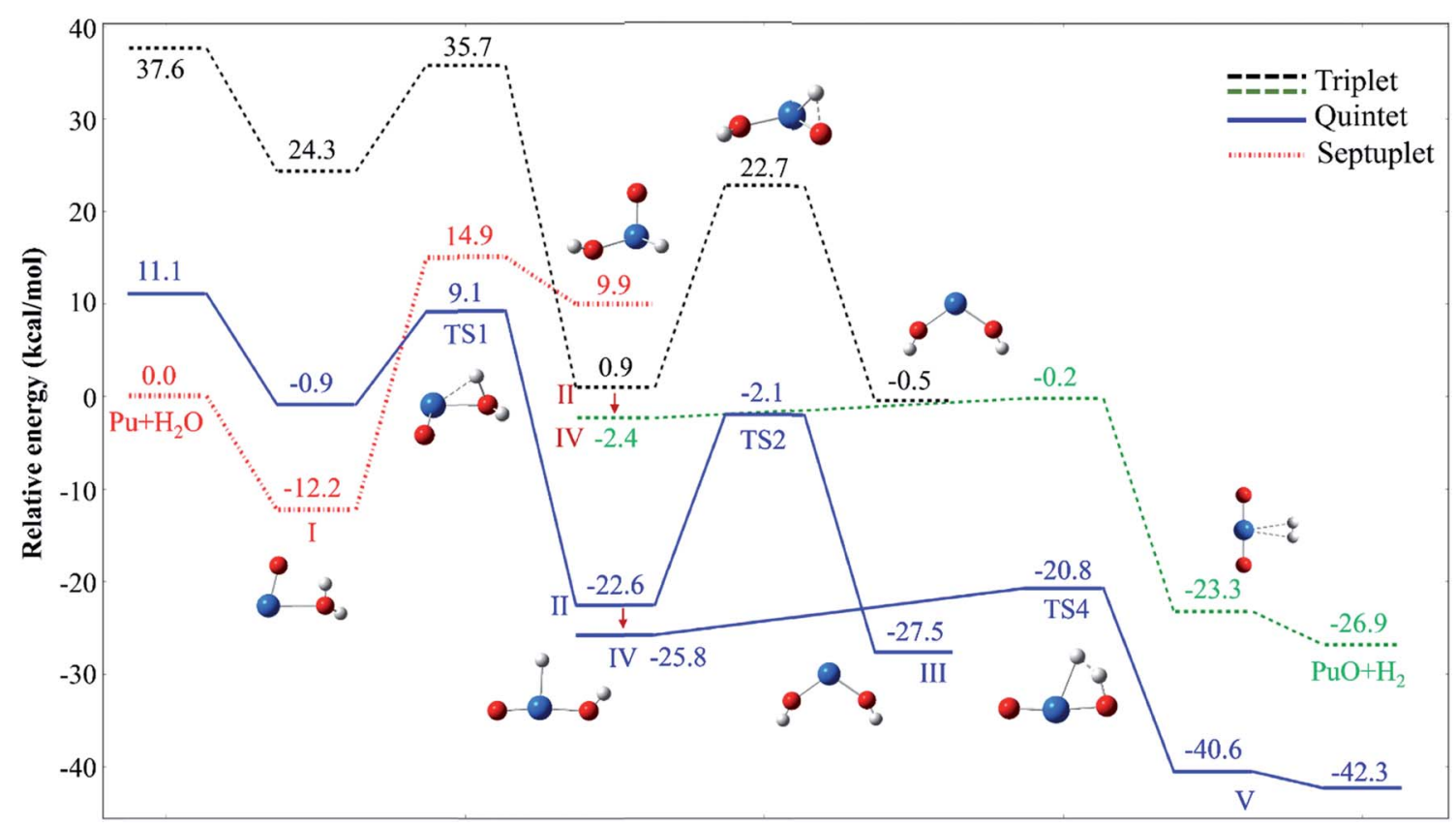

Fig. 2 Potential energy profiles for the reaction of $\mathrm{PuO}+\mathrm{H}_{2} \mathrm{O}$ (path A) at the PW91/SDD levels of theory. 
Table 2 Relative energies ( $\mathrm{kcal} \mathrm{mol}^{-1}$ ) of the stationary points on the $\mathrm{PuO}+\mathrm{H}_{2} \mathrm{O}$ potential energy surface

\begin{tabular}{|c|c|c|c|c|c|c|c|c|c|c|}
\hline & $\mathbf{I}(7)$ & TS1 (5) & II (5) & TS2 (5) & TS3 (7) & III (7) & IV (5) & TS4 (5) & $\mathbf{V}(5)$ & $\mathrm{PuO}_{2}+\mathrm{H}_{2}$ \\
\hline $\mathrm{B}^{2} \mathrm{LYP}^{a}$ & 6.768 & 33.382 & 0.000 & 22.044 & 11.217 & -22.239 & -0.493 & 13.045 & -7.917 & -11.782 \\
\hline${\mathrm{B} 3 \mathrm{PW} 91^{a}}^{a}$ & 6.817 & 32.309 & 0.000 & 18.603 & 8.921 & -26.223 & -0.948 & 8.646 & -9.354 & -16.192 \\
\hline $\mathrm{PW}^{a}{ }^{a}$ & 10.308 & 37.490 & 0.000 & 20.496 & 11.865 & -18.660 & -3.253 & 1.798 & -18.015 & -19.781 \\
\hline$\left\langle S^{2}\right\rangle^{b}$ & 12.026 & 6.862 & 6.068 & 6.703 & 12.020 & 12.009 & 6.083 & 6.072 & 6.064 & \\
\hline$\left\langle S^{2}\right\rangle^{c}$ & 12.032 & 6.893 & 6.075 & 6.732 & 12.026 & 12.015 & 6.083 & 6.077 & 6.064 & \\
\hline
\end{tabular}

${ }^{a}$ SDD for Pu and 6-311++G(d,p) for O and H atoms. ${ }^{b}$ Expected value of $S^{2}$ at the B3LYP/SDD level of theory. ${ }^{c}$ Expected value of $S^{2}$ at the B3PW91/ SDD level of theory. ${ }^{d}$ Expected value of $S^{2}$ at the PW91/SDD level of theory. ${ }^{e}$ Expected value of $S^{2}$ at the PW91/SDD level of theory.

As can be seen in Fig. 2, the path A, the system proceeds to form the first insertion intermediate (II) $\mathrm{H}-\mathrm{OPuOH}$ through the TS1 in which the PuO is inserted into one of the O-H. The first transition state TS1 with an activation barrier of $9.1 \mathrm{kcal} \mathrm{mol}^{-1}$ at the PW91/SDD level, and the imaginary frequency of $-1219.12 \mathrm{~cm}^{-1}$ correspond primarily to the migration of the $\mathrm{H}$ atom from the $\mathrm{O}$ atom to the $\mathrm{Pu}$ atom. In this process, the system involves crossings between surfaces of quintet and septuplet spin states, and the minimum energy path changes from septuplet to quintet state.

After the $\mathrm{OHPuOH}$ intermediate, the reaction will proceed along two channels. The first one is the isomerization of $\mathrm{OHPuOH}$ to form $\mathrm{HO}-\mathrm{Pu}-\mathrm{OH}$ (III). Alone the quintet state surface this intermediate carried on to isomerization via TS2 transition state, which lay $2.1 \mathrm{kcal} \mathrm{mol}^{-1}$ below the asymptotes, with an activation barrier of $20.5 \mathrm{kcal} \mathrm{mol}^{-1}$ at the PW91/SDD levels of theory. The imaginary frequency of TS2 was $-1143.37 \mathrm{~cm}^{-1}$, corresponding to the movement of the second $\mathrm{H}$ atom from the $\mathrm{O}$ atom to the $\mathrm{Pu}$ atom. Our results on $\mathrm{HO}-\mathrm{Pu}-$ $\mathrm{OH}$ predicted that this isomeric product have a septuplet $\left({ }^{7} \mathrm{~A}\right)$ ground state.

Another channel is dehydrogenation process. As can be seen, in this process, the intermediate II product first passes through a no-threshold isomerization process to form intermediate $\mathbf{I V}$, and the corresponding molecular structure changes from triangular pyramid (II) to plane (IV). The change in energy during this process is relatively small, $3.2 \mathrm{kcal} \mathrm{mol}^{-1}$ with the PW91/SDD method. From IV, the second $\mathrm{H}$ atom migrating from oxygen to plutonium evolved into a hydrogen complex $\left(\mathrm{H}_{2}\right)$ $\mathrm{PuO}$, complex $\mathbf{V}$ in Fig. 2. This process needs to overcome a fourcenter transition state TS4, which lay $20.8 \mathrm{kcal} \mathrm{mol}^{-1}$ below the asymptotes, with an imaginary frequency of $-1133.11 \mathrm{~cm}^{-1}$ and described a motion in which the two hydrogen atoms moving together. This dehydrogenation of $\mathrm{PuO}+\mathrm{H}_{2} \mathrm{O}$ was calculated to be exothermic at $-42.3 \mathrm{kcal} \mathrm{mol}^{-1}$ at PW91/SDD level of theory.

For path B, as shown in Fig. 3, the path B is also an isomerization process, and the isomeric product is $\mathrm{HO}-\mathrm{Pu}-\mathrm{OH}$ (III). Comparison of path A and path B reveals that these two channels have the same isomeric product but undergo two different transition states. Compared to the path A, the path B can be directly isomerism from the initial complex $\mathbf{I}$, only need the system overcomes a transition state TS3. The TS3 lies at $-10.7 \mathrm{kcal} \mathrm{mol}^{-1}$ below the reactant asymptote, and with an imaginary frequency of $-1121.40 \mathrm{~cm}^{-1}$ and corresponds mainly to the movement of $\mathrm{H}$ atom from $\mathrm{O}_{\mathrm{yl}}$ atom (the $\mathrm{O}$ atom of $\mathrm{H}_{2} \mathrm{O}$ molecule) to the $\mathrm{O}$ atom of PuO molecule.

The relative energies of selected stationary species for the $\mathrm{PuO}+\mathrm{H}_{2} \mathrm{O}$ reaction at all the studied methods are collected in Table 2. We can see that energies were consistent in most case except for B3LYP/SDD which overestimated the relative energy of TS3 and TS4. In addition, we checked the $\left\langle S^{2}\right\rangle$ values to ensure the spin contamination was minimal.

As discussed above, this reaction involves crossing between surfaces of quintet and septuplet spin states. It is worth mentioning that these intersystem crossings play an important role in the progress of the reaction, since it characterizes where the transition is most likely to take places. The MECPs between states of different spin have been located by the sobMECP method. We first determine the MECP between the septuplet and quintet surfaces in the region from complex I to TS1, marked as $\operatorname{MECP}(7-5)$, and the MECP between the septuplet and triplet surfaces in the region from TS1 to complex II, marked as $\operatorname{MECP}(7-3)$. The molecular structures of MECPs at the PW91/SDD level of theory are shown in Fig. 4. The $\operatorname{MECP}(7-5)$ has a nonplanar geometry in which the $\mathrm{Pu}-\mathrm{O}_{\mathrm{yl}}, \mathrm{Pu}-\mathrm{H}$ and $\mathrm{O}-\mathrm{H}$ bond lengths are 2.218, 2.189 and $1.368 \AA$, respectively. This geometry is very similar to TS1, means that it is a late crossing point, leading to the barrier height from 14.9 to $9.1 \mathrm{kcal} \mathrm{mol}^{-1}$ at the PW91/SDD level. For the MECP(7-3), the $\mathrm{Pu}-\mathrm{O}_{\mathrm{yl}}$ and $\mathrm{Pu}-\mathrm{H}$ bond lengths are 2.133 and $2.136 \AA$, and the $\mathrm{H}-\mathrm{Pu}-\mathrm{O}_{\mathrm{yl}}$ angle is $57.86^{\circ}$.

Analysis of the whole reaction of $\mathrm{PuO}+\mathrm{H}_{2} \mathrm{O}$, we found that the reaction mechanism is similar with the activation of $\mathrm{H}_{2} \mathrm{O}$ by

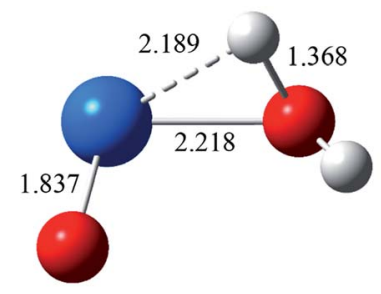

MECP (7-5)

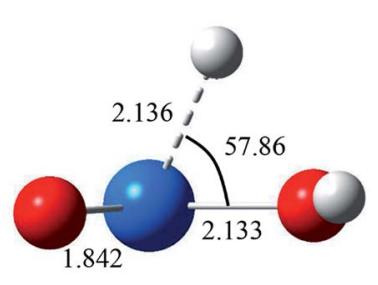

$\operatorname{MECP}(7-3)$
Fig. 4 Structures and selected geometric parameters of MECP on the $\mathrm{PuO}+\mathrm{H}_{2} \mathrm{O}$ potential energy surface optimized at the PW91/SDD levels of theory. Bond distances are in $\AA$, and angles are in degrees. 




I (7)

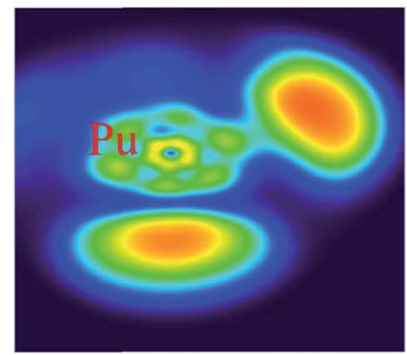

TS2 (5)

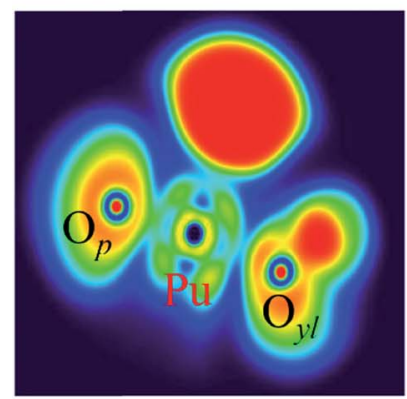

IV (5)

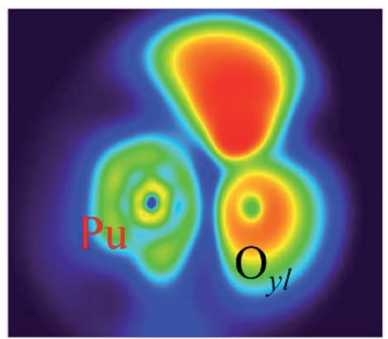

TS1 (5)

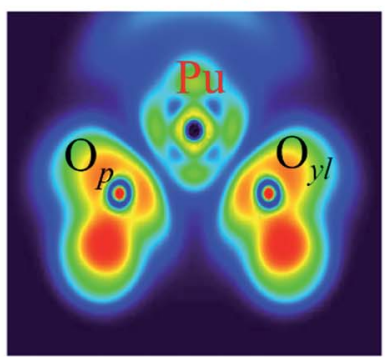

III (7)

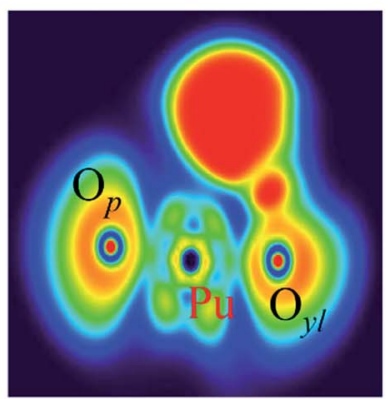

TS4 (5)



II (5)

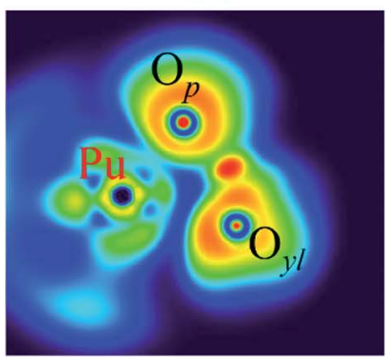

TS3 (7)

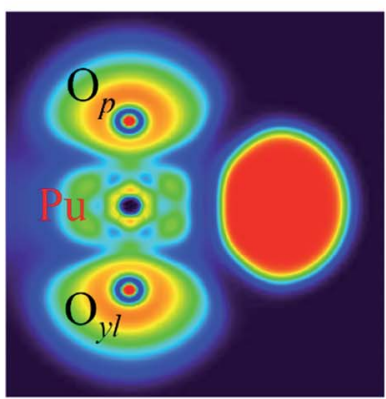

$\mathrm{V}(5)$

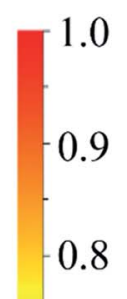

$-0.7$

$-0.6$

$-0.5$

$-0.4$

$-0.3$

0.2

0.1

0.0

Fig. 5 ELF shaded surfaces with projection maps of stationary points on the PuO $+\mathrm{H}_{2} \mathrm{O}$ potential energy surface optimized at the PW91/SDD levels of theory.

actinide atoms and ions. ${ }^{21-24,50-52}$ The reaction mechanisms according to the universal channel proposed, the first step is the formation of a actinide $-\mathrm{OH}_{2}$ complex followed with an $\mathrm{O}-\mathrm{H}$ bond broke by the insertion of the actinide molecule. After that the first insertion intermediate will be generated, and this process is usually the key step of the whole reaction, with the largest reaction coefficients. In addition, this process always involves a crossings between surfaces of different spin states, with the exception of $\mathrm{Pu}+\mathrm{H}_{2} \mathrm{O},{ }^{21}$ which takes place alone the minimum energy path septuplet state surface. The following step is migration of second $\mathrm{H}$ atom of $\mathrm{H}_{2} \mathrm{O}$ molecule to the actinide, and the isomerization or hydrogen elimination are take places. Our previous studies show that this insertion intermediates have relatively long lifetimes to restructuring. Take $\mathrm{Pu}+\mathrm{H}_{2} \mathrm{O}$ as an example, ${ }^{21}$ the lifetime of $\mathrm{HPuOH}$ intermediate was found to be almost $137 \mathrm{fs}$. From the perspective of energy barriers, it is difficult to oxidize PuO by water molecules than $\mathrm{Pu}$ atoms at room temperature. The activation energy barrier of the first $\mathrm{O}-\mathrm{H}$ bond for $\mathrm{PuO}+\mathrm{H}_{2} \mathrm{O}$ is $21.3 \mathrm{kcal} \mathrm{mol}^{-1}$ at PW91/SDD levels of theory, while this barrier for $\mathrm{Pu}+\mathrm{H}_{2} \mathrm{O}$ is $15.8 \mathrm{kcal} \mathrm{mol}^{-1}$. This view is also confirmed in later reaction rate analysis.

\section{Bonding characteristics}

In this section, we conducted the ELF, AIM and Mayer bond orders analysis to get a deeper understanding of the bond characteristics evolution. It is worth emphasizing that ELF + AIM analysis are powerful tools to analyzing the nature of the interaction between atoms, and have been successfully used in the actinide system..$^{47-53}$

The ELF shaded surfaces with projection maps of stationary points on the $\mathrm{PuO}+\mathrm{H}_{2} \mathrm{O}$ potential energy surface optimized at the PW91/SDD levels of theory are displayed in Fig. 5. The AIM parameters of the main BCPs of each species are listed in Table 3. These topological parameters include electron density $\rho(r)$ and its Laplacian $\nabla^{2} \rho(r)$, the kinetic $G(r)$ and potential energy density $V(r), H(r)$ is the total energy density. $H(r)$ was used as a criterion, ${ }^{54}$ negative $H(r)$ corresponds to covalent interactions and positive $H(r)$ correspond to closed-shell interactions. $\lambda_{1}$ and $\lambda_{2}$ are the eigenvalues of the Hessian of the energy density, and $\varepsilon=\lambda_{1} / \lambda_{2}-1$ denotes the ellipticity of the BCP. The $\varepsilon$ was used as a measure of asphericity of the curvature of the $\rho(r)$ in BCP, and served as a criterion to indicate the $\pi$ nature of bonds. ${ }^{5,56}$ 
Table 3 Topological properties of the charge density calculated at the $(3,-1)$ BCPs for selected species involved in the reaction pathway ${ }^{a}$

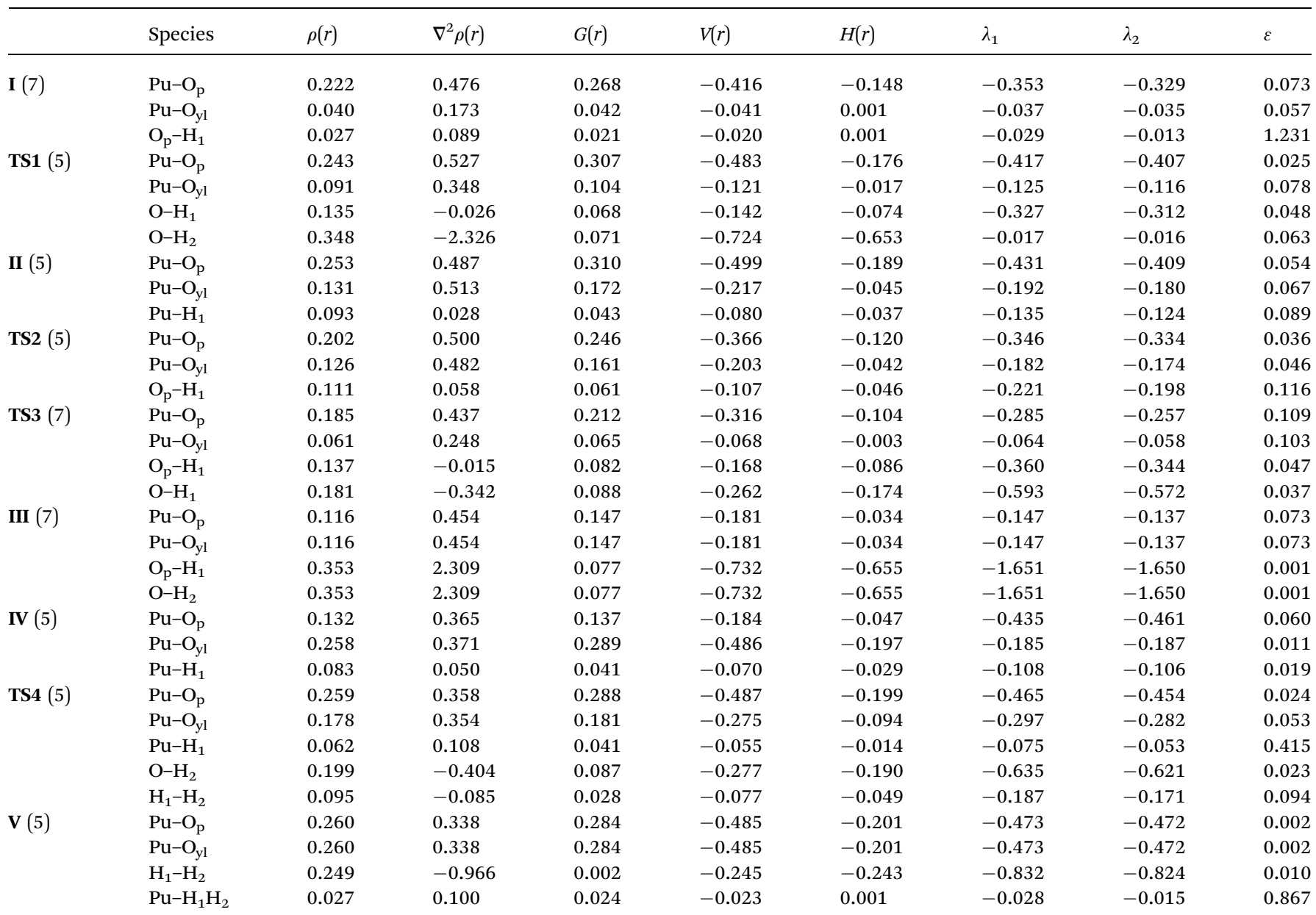

${ }^{a} \mathrm{O}_{\mathrm{p}}$ is the $\mathrm{O}$ atom of $\mathrm{PuO}$, and $\mathrm{O}_{\mathrm{yl}}$ is the $\mathrm{O}$ atom of $\mathrm{H}_{2} \mathrm{O}$.

As shown in Fig. 5, for first complex $\mathrm{OPu}-\mathrm{OH}_{2}$, there is no disynaptic valence basin between $\mathrm{Pu}$ and $\mathrm{O}_{\mathrm{yl}}$ atom, which means that there is no electron concentration between these two atoms. The AIM analysis results show that these is a $(3,-1)$ $\mathrm{BCP}$ between $\mathrm{Pu}$ and $\mathrm{O}_{\mathrm{yl}}$ atom, and the corresponding electron density $\rho(r)$ is 0.04 and the $H(r)$ is 0.001 . Positive $H(r)$ value means that $\mathrm{Pu}-\mathrm{O}_{\mathrm{yl}}$ interaction is a closed-shell interaction in complex I. In the case of TS1, the ELF and AIM results indicate that the $\mathrm{Pu}-\mathrm{O}_{\mathrm{yl}}$ bond is gradually formed in this process. Although the corresponding $H(r)$ is small $(-0.017)$, it is still an indicator of the increase in the electronic density of the $\mathrm{Pu}-\mathrm{O}_{\mathrm{yl}}$ BCP. Besides, the $H(r)$ of the $\mathrm{O}-\mathrm{H}_{1}$ bond is drops strongly compared to the $\mathrm{O}-\mathrm{H}_{2}$ bond, which means that the $\mathrm{O}-\mathrm{H}_{1}$ bond has a tendency to break.

In regard to the complex II, $\mathrm{H}-\mathrm{OPuOH}$, the ELF and AIM analysis shows that in this process the system involves a significantly change. The ELF result indicates that the disynaptic $\mathrm{V}\left(\mathrm{O}-\mathrm{H}_{1}\right)$ basin has been replaced by the $\mathrm{V}\left(\mathrm{Pu}-\mathrm{H}_{1}\right)$ basin, which means that the $\mathrm{Pu}-\mathrm{H}_{1}$ bond was formed. The topological analysis shows there is a $(3,-1)$ BCP between Pu and $\mathrm{H}_{1}$ atoms, and the $H(r)$ is -0.080 reveals that this $\mathrm{Pu}-\mathrm{H}_{1}$ bond belongs to covalent interactions. Besides, ELF and AIM analysis reveals the interaction of $\mathrm{Pu}-\mathrm{O}_{\mathrm{yl}}$ was strengthened, which was reflected by the increased $H(r)$ of $\mathrm{Pu}-\mathrm{O}_{\mathrm{yl}}$.

In terms of TS2, the ELF and AIM analysis indicates that there is no disynaptic $\mathrm{V}\left(\mathrm{Pu}-\mathrm{H}_{1}\right)$ basin and $(3,-1) \mathrm{BCP}$ between $\mathrm{Pu}$ and $\mathrm{H}_{1}$ atoms, which means that this $\mathrm{Pu}-\mathrm{H}_{1}$ bond has been broken in this process. Besides, the $\rho(r)$ of $\mathrm{Pu}-\mathrm{O}_{\mathrm{p}}$ and $\mathrm{Pu}-\mathrm{O}_{\mathrm{yl}}$ are decreasing, due to the sustained isomerization of molecular structure. In the case of the isomeric product $\mathrm{HO}-\mathrm{Pu}-\mathrm{OH}$ (III), the corresponding ELF projection map like a beautiful butterfly.

Table 4 Mayer bond order analysis for all of the lowest-energy spin state species involved in the reaction of $\mathrm{PuO}+\mathrm{H}_{2} \mathrm{O}$ at the PW91 level of theory

\begin{tabular}{llllllllll}
\hline Species & I & TS1 & II & TS2 & TS3 & III & IV & TS4 & V \\
\hline $\mathrm{Pu}-\mathrm{O}_{\mathrm{p}}$ & 1.64 & 1.81 & 1.82 & 1.39 & 1.29 & 0.73 & 1.75 & 1.75 & 1.72 \\
$\mathrm{Pu}-\mathrm{O}_{\mathrm{yl}}$ & 0.15 & 0.39 & 0.80 & 0.79 & 0.37 & 0.73 & 0.90 & 1.18 & 1.72 \\
$\mathrm{Pu}-\mathrm{H}_{1}$ & & 0.66 & 0.93 & 0.72 & & & 0.89 & 0.67 & 0.11 \\
$\mathrm{Pu}-\mathrm{H}_{2}$ & & & & & & & & 0.23 & 0.11 \\
$\mathrm{O}_{\mathrm{p}}-\mathrm{H}_{1}$ & & & & 0.19 & 0.48 & 0.88 & & & \\
$\mathrm{O}-\mathrm{H}_{1}$ & 0.87 & 0.16 & & & 0.50 & & & 0.43 & \\
$\mathrm{O}-\mathrm{H}_{2}$ & 0.91 & 0.88 & 0.87 & 0.87 & 0.90 & 0.88 & 0.87 & 0.49 & \\
$\mathrm{H}_{1}-\mathrm{H}_{2}$ & & & & & & & & & 0.89
\end{tabular}



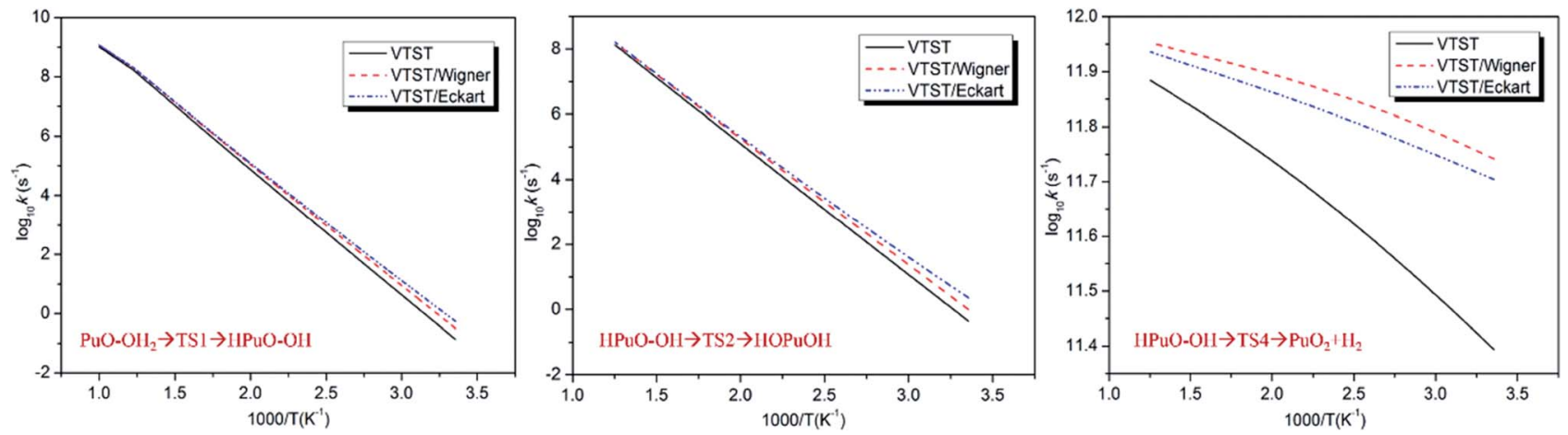

Fig. 6 Rate constants $\log _{10} k$ with $1000 / T$ plots of $\mathrm{PuO}+\mathrm{H}_{2} \mathrm{O}$ reaction.

From the ELF analysis, we can see that the $\mathrm{O}_{\mathrm{p}}-\mathrm{H}_{2}$ bond has been formed as evidenced by the disynaptic $\mathrm{V}\left(\mathrm{O}_{\mathrm{p}}-\mathrm{H}_{2}\right)$ basin. The AIM results reveal that these topological parameters have mirror symmetry, and all of these chemical bonds belong to covalent interactions.

The ELF and AIM analysis of the IV show that there are $\mathrm{V}(\mathrm{Pu}-$ $\left.\mathrm{H}_{1}\right)$ and $\mathrm{V}\left(\mathrm{Pu}-\mathrm{O}_{\mathrm{yl}}\right)$ disynaptic valence basins, and an increase in the $\rho(r)$ of $\mathrm{Pu}-\mathrm{O}_{\mathrm{yl}}$. In the case of TS4, these two $\mathrm{H}$ atoms are attracted to each other and gradually form bond, which proved by the $\mathrm{V}\left(\mathrm{H}_{1}-\mathrm{H}_{2}\right)$ disynaptic valence basin and the negative value of $H(r)-0.049$. This trend is more pronounced in the complex $\mathbf{V}$. As can be seen in the Table 3, the $H(r)$ of $\mathrm{H}_{1}-\mathrm{H}_{2}$ in $\mathbf{V}$ is -0.243 , and there is a BCP between $\mathrm{Pu}$ atom and $\mathrm{H}_{1}-\mathrm{H}_{2}$ group with $H(r)$ is 0.001 , these values reveal that the $\mathrm{Pu}-\left(\mathrm{H}_{1} \mathrm{H}_{2}\right)$ interaction with the closed-shell characteristic.

In the case of the critical transition state TS3 in path $\mathrm{B}$, the $\mathrm{H}_{1}$ atom has been bonded to the $\mathrm{O}_{\mathrm{p}}$ atom of $\mathrm{PuO}$, as evidenced by the $\mathrm{V}\left(\mathrm{O}_{\mathrm{p}}-\mathrm{H}_{1}\right)$ disynaptic valence basin and the corresponding $H(r)$ is -0.086 . Meanwhile, the interaction of $\mathrm{Pu}-\mathrm{O}_{\mathrm{yl}}$ was enhanced compared to the initial complex I. A higher $\rho(r)$ (0.061) and more negative $H(r)(-0.003)$ were found for $\mathrm{Pu}-\mathrm{O}_{\mathrm{yl}}$ in TS3 than in complex I.

As mentioned above, the ellipticity $\varepsilon$ is the index of the $\pi$ nature of the bonds. From Table 3, we can see that in complex I, the $\varepsilon$ of $\mathrm{Pu}-\mathrm{O}_{\mathrm{p}}$ and $\mathrm{Pu}-\mathrm{O}_{\mathrm{yl}}$ are 0.073 and 0.057 respectively. In comparison, both the $\varepsilon$ of $\mathrm{Pu}-\mathrm{O}_{\mathrm{p}}$ and $\mathrm{Pu}-\mathrm{O}_{\mathrm{yl}}$ in product $\mathrm{V}$ are 0.002. This trend reveals that the $\pi$ nature of $\mathrm{Pu}-\mathrm{O}_{\mathrm{p}}$ and $\mathrm{Pu}-\mathrm{O}_{\mathrm{yl}}$ was reduced as the reaction progresses.
Mayer bond orders analysis for all of the lowest-energy spin state species are listed in Table 4 . As can be seen, the conclusions of Mayer bond order analysis are agree with the ELF and AIM analysis. In complex I, the $\mathrm{Pu}-\mathrm{O}_{\mathrm{yl}}$ bond order is 0.15 indicating there is no covalent interaction between these two atoms. As the $\mathrm{PuO}+\mathrm{H}_{2} \mathrm{O}$ reaction proceeds, the interaction between $\mathrm{Pu}$ atom and ligands is strengthening, as evidenced by the increasing of the $\mathrm{Pu}-\mathrm{O}_{\mathrm{yl}}$ bond order.

\section{Reaction rate constants}

Rate coefficients $(k)$ were calculated using the VTST method, and the energies and frequencies data used in this section were obtained by PW91/SDD in the reaction mechanism. In addition, the one-dimensional tunneling effects Wigner and Eckart were taken into account.

Firstly, we calculated the variational effect of the titled reaction, the results indicate that both the barriers of classical potential energy $\left(V_{\mathrm{MEP}}\right)$ and the ground state adiabatic potential energy $\left(V_{\mathrm{a}}^{\mathrm{G}}\right)$ were located at the original transition state, which means that there is no variational effect, and $k^{\mathrm{VTST}}$ is equal to the $k^{\mathrm{TST}}$. The concrete calculation of the rate constants is carried out according to the following expression ${ }^{45}$

$$
k^{\mathrm{TST}}(T)=\sigma \frac{k_{\mathrm{b}}}{h}\left(\frac{R T}{P^{0}}\right)^{\Delta n} \mathrm{e}^{-\frac{\Delta G^{0, \ddagger}(T)}{k_{\mathrm{b}} T}}
$$

where $\sigma$ is the reaction path degeneracy, $k_{\mathrm{b}}$ and $h$ are the Boltzmann's constant and Planck's constant, respectively. $T$ is the temperature, $P$ is the pressure and $P^{0}=1$ bar. $\Delta n$ is the parameter

Table 5 Calculated thermal rate constants for the $\mathrm{PuO}+\mathrm{H}_{2} \mathrm{O}$ reaction at the PW91/SDD level of theory

\begin{tabular}{|c|c|c|c|c|c|c|c|c|c|}
\hline \multirow[b]{2}{*}{$T(\mathrm{~K})$} & \multicolumn{3}{|c|}{$\mathrm{PuO}-\mathrm{OH}_{2} \rightarrow \mathrm{HPuO}-\mathrm{OH}$} & \multicolumn{3}{|c|}{$\mathrm{HPuO}-\mathrm{OH} \rightarrow \mathrm{HOPuOH}$} & \multicolumn{3}{|c|}{$\mathrm{HPuO}-\mathrm{OH} \rightarrow \mathrm{PuO}_{2}+\mathrm{H}_{2}$} \\
\hline & $k^{\mathrm{VTST}}$ & $k^{\mathrm{VTST} / \mathrm{W}}$ & $k^{\mathrm{VTST} / \mathrm{Eck}}$ & $k^{\mathrm{VTST}}$ & $k^{\mathrm{VTST} / \mathrm{W}}$ & $k^{\mathrm{VTST} / \mathrm{Eck}}$ & $k^{\mathrm{VTST}}$ & $k^{\mathrm{VTST} / \mathrm{W}}$ & $k^{\mathrm{VTST} / \mathrm{Eck}}$ \\
\hline 298 & 0.135 & 0.317 & 0.548 & 0.434 & 0.987 & 2.271 & $2.47 \times 10^{11}$ & $5.51 \times 10^{11}$ & $5.06 \times 10^{11}$ \\
\hline 300 & 0.168 & 0.391 & 0.668 & 0.533 & 1.204 & 2.712 & $2.51 \times 10^{11}$ & $5.55 \times 10^{11}$ & $5.09 \times 10^{11}$ \\
\hline 350 & $1.70 \times 10$ & $3.36 \times 10$ & $4.64 \times 10$ & $4.37 \times 10$ & $8.40 \times 10$ & $1.31 \times 10^{2}$ & $3.39 \times 10^{11}$ & $6.42 \times 10^{11}$ & $5.83 \times 10^{11}$ \\
\hline 400 & $5.52 \times 10^{2}$ & $9.63 \times 10^{2}$ & $1.18 \times 10^{3}$ & $1.19 \times 10^{3}$ & $2.04 \times 10^{3}$ & $2.69 \times 10^{3}$ & $4.19 \times 10^{11}$ & $7.04 \times 10^{11}$ & $6.43 \times 10^{11}$ \\
\hline 450 & $8.37 \times 10^{3}$ & $1.32 \times 10^{4}$ & $1.53 \times 10^{4}$ & $1.58 \times 10^{4}$ & $2.46 \times 10^{4}$ & $2.95 \times 10^{4}$ & $4.88 \times 10^{11}$ & $7.51 \times 10^{11}$ & $6.69 \times 10^{11}$ \\
\hline 500 & $7.44 \times 10^{4}$ & $1.09 \times 10^{5}$ & $1.21 \times 10^{5}$ & $1.24 \times 10^{5}$ & $1.81 \times 10^{5}$ & $2.05 \times 10^{5}$ & $5.47 \times 10^{11}$ & $7.85 \times 10^{11}$ & $7.29 \times 10^{11}$ \\
\hline 550 & $4.49 \times 10^{5}$ & $6.25 \times 10^{5}$ & $6.75 \times 10^{5}$ & $6.78 \times 10^{5}$ & $9.31 \times 10^{5}$ & $1.02 \times 10^{6}$ & $5.97 \times 10^{11}$ & $8.12 \times 10^{11}$ & $7.60 \times 10^{11}$ \\
\hline 600 & $2.02 \times 10^{6}$ & $2.69 \times 10^{6}$ & $2.85 \times 10^{6}$ & $2.78 \times 10^{6}$ & $3.66 \times 10^{6}$ & $3.92 \times 10^{6}$ & $6.40 \times 10^{11}$ & $8.34 \times 10^{11}$ & $7.86 \times 10^{11}$ \\
\hline
\end{tabular}


that distinguishes the bimolecular and unimolecular reaction. $\Delta G^{0, \ddagger}(T)$ is the standard Gibbs free energy of activation.

The predicted rate constants $\log _{10} k$ with $1000 / T$ graphics of $\mathrm{PuO}+\mathrm{H}_{2} \mathrm{O}$ are presented in Fig. 6, and rate constants $k$ at 298 and $600 \mathrm{~K}$ are collected in Table 5 . By analyzing these data, we can see that the $\mathrm{HPuO}-\mathrm{OH} \rightarrow \mathrm{PuO}_{2}+\mathrm{H}_{2}$ is the fastest part of the whole reaction. The process of dissociating the $\mathrm{O}-\mathrm{H}$ bond of $\mathrm{H}_{2} \mathrm{O}$ at room temperature is very slow, but as the temperature rises, this progress getting more faster. In contrast, the elevated temperature did not significantly increase the rate of dehydrogenation. By comparison, we found that the tunneling effects in the dehydrogenation process were more obvious than in the dissociating $\mathrm{O}-\mathrm{H}$ bond one.

\section{Conclusions}

The present work describes a systematic investigation of the gas phase $\mathrm{PuO}$ react with $\mathrm{H}_{2} \mathrm{O}$ molecule. The detailed mechanism, topological properties and rate constants were obtained. The main conclusions are summarized as follows,

(1) Two reaction channels were found, there are isomerization and dehydrogenation. The later one was the minimum energy reaction pathway. Our results reveal that this process involve crossing between surfaces of quintet and septuplet spin states, and the corresponding MECPs were located.

(2) Topological property analysis can make us understand the nature of the bonding behavior along the reaction. Our ELF and AIM results show that at the beginning of the reaction, the $\mathrm{PuO}$ and $\mathrm{H}_{2} \mathrm{O}$ molecule are getting close to each other by electrostatic interaction and form an initial complex $\mathbf{I}$, and $\mathrm{Pu}-\mathrm{O}_{\mathrm{yl}}$ interaction is a closed-shell interaction in this complex. As the reaction progresses, the covalent properties are gradually reflected between the $\mathrm{Pu}-\mathrm{O}_{\mathrm{yl}}$ atoms.

(3) The reaction rate constant results show that it is not easy to dissociate the first $\mathrm{O}-\mathrm{H}$ bond by $\mathrm{PuO}$ at room temperature. Once the $\mathrm{O}-\mathrm{H}$ bonds were dissociated, the remaining process will be exothermic.

\section{Conflicts of interest}

There are no conflicts of interest to declare.

\section{Acknowledgements}

This work is supported by National Natural Science Foundation of China (NSFC) (Grant No. 11604187, No. 11647040 and No. 11575099), and Open Fund of Key Laboratory of Advanced Reactor Engineering and Safety, Ministry of Education (Tsinghua University, China).We are very grateful to Dr Sobereva for many helpful discussions and providing us with the Multiwfn package. We would like to thank the reviewers for the valuable suggestions on improving our paper.

\section{Notes and references}

1 J. M. Haschke, T. H. Allen and L. A. Morales, Los Alamos Sci., 2000, 26, 252-273.
2 J. M. Haschke, T. H. Allen and L. A. Morales, Science, 2000, 287, 285-287.

3 P. A. Korzhavyi, L. Vitos, D. A. Andersson and B. Johansson, Nat. Mater., 2004, 4, 225-228.

4 J. K. Gibson, Int. J. Mass Spectrom., 2000, 202, 19-29.

5 J. K. Gibson, J. Mass Spectrom., 2001, 36, 284-293.

6 M. Santos, J. Marçalo, A. Pires de Matos, J. K. Gibson and R. G. Haire, J. Phys. Chem. A, 2002, 106, 7190-7194.

7 J. K. Gibson, Int. J. Mass Spectrom., 2002, 216, 185-202.

8 J. M. Haschke, T. H. Allen and L. A. Morales, J. Alloys Compd., 2001, 314, 78-91.

9 J. K. Gibson, R. G. Haire, M. Santos, J. Marçalo and A. Pires de Matos, J. Phys. Chem. A, 2005, 109, 2768-2781.

10 D. Rios, M. C. Michelini, A. F. Lucena, J. Marçalo, T. H. Bray and J. K. Gibson, Inorg. Chem., 2012, 51, 6603-6614.

11 J. K. Gibson, R. G. Haire, J. Marçalo, M. Santos, A. Pires de Matos, M. K. Mrozik, R. M. Pitzer and B. E. Bursten, Organometallics, 2007, 26, 3947-3956.

12 J. K. Gibson, R. G. Haire, J. Marçalo, M. Santos, J. P. Leal, A. Pires de Matos, R. Tyagi, M. K. Mrozik, R. M. Pitzer and B. E. Bursten, Eur. Phys. J. D, 2007, 45, 133-138.

13 J. P. Blaudeau, S. A. Zygmunt, L. A. Curtiss, D. T. Reed and B. E. Bursten, Chem. Phys. Lett., 1999, 310, 347-354.

14 X. Wu and A. K. Ray, Phys. B, 2001, 293, 362-375.

15 Z. Cao and K. Balasubramanian, J. Chem. Phys., 2005, 123, 114309.

16 L. V. Moskaleva, A. V. Matveev, J. Dengler and N. Rosch, Phys. Chem. Chem. Phys., 2006, 8, 3767-3773.

17 B. Schimmelpfennig, T. Privalov, U. Wahlgren and I. Grenthe, J. Phys. Chem. A, 2003, 107, 9705-9711.

18 K. Balasubramanian, T. E. Felter, T. Anklam, T. W. Trelenberg and W. McLean II, J. Alloys Compd., 2007, 444-445, 447-452.

19 K. J. de Almeida and H. A. Duarte, Organometallics, 2009, 28, 3203-3211.

20 H. M. Steele, D. Guillaumont and P. Moisy, J. Phys. Chem. A, 2013, 117, 4500-4505.

21 P. Li, W. X. Niu, T. Gao and H. Y. Wang, ChemPhysChem, 2014, 15, 3078-3088.

22 M. d. C. Michelini, N. Russo and E. Sicilia, Angew. Chem., Int. Ed., 2006, 45, 1095-1099.

23 M. d. C. Michelini, N. Russo and E. Sicilia, J. Am. Chem. Soc., 2007, 129, 4229-4239.

24 B. Y. Liang, R. D. Hunt, G. P. Kushto, L. Andrews, J. Li and B. E. Bursten, Inorg. Chem., 2005, 44, 2159-2168.

25 E. Di Santo, M. C. Michelini and N. Russo, J. Phys. Chem. A, 2009, 113, 14699-14705.

26 P. Li, W. Niu, X. F. Tian, T. Gao and H. Y. Wang, J. Phys. Chem. A, 2013, 117, 3761-3770.

27 P. Li, W. Niu and T. Gao, RSC Adv., 2014, 4, 29806-29817.

28 B. Ao, R. Qiu, H. Lu, X. Ye, P. Shi, P. Chen and X. Wang, J. Phys. Chem. C, 2015, 119, 101-108.

29 R. Qiu, Y. Zhang and B. Ao, Sci. Rep., 2017, 7, 12167.

30 C. Lee, W. Yang and R. G. Parr, Phys. Rev. B: Condens. Matter Mater. Phys., 1988, 37, 785-789.

31 A. D. Becke, J. Chem. Phys., 1993, 98, 5648-5652.

32 A. D. Becke, Phys. Rev. A, 1998, 38, 3098-3100. 
33 C. Adamo and V. Barone, J. Chem. Phys., 1999, 110, 61586170.

34 J. P. Perdew, K. Burke and Y. Wang, Phys. Rev. B: Condens. Matter Mater. Phys., 1996, 54, 16533-16539.

35 W. Küchle, M. Dolg, H. Stoll and H. Preuss, J. Chem. Phys., 1994, 100, 7535-7542.

36 R. Krishnan, J. S. Binkley, R. Seeger and J. A. Pople, J. Chem. Phys., 1980, 72, 650-654.

37 M. J. Frisch, G. W. Trucks, H. B. Schlegel, G. E. Scuseria, M. A. Robb, J. R. Cheeseman, J. A. Montgomery Jr, T. Vreven, K. N. Kudin, J. C. Burant, J. M. Millam, S. S. Iyengar, J. Tomasi, V. Barone, B. Mennucci, M. Cossi, G. Scalmani, N. Rega, G. A. Petersson, H. Nakatsuji, M. Hada, M. Ehara, K. Toyota, R. Fukuda, J. Hasegawa, M. Ishida, T. Nakajima, Y. Honda, O. Kitao, H. Nakai, M. Klene, X. Li, J. E. Knox, H. P. Hratchian, J. B. Cross, V. Bakken, C. Adamo, J. Jaramillo, R. Gomperts, R. E. Stratmann, O. Yazyev, A. J. Austin, R. Cammi, C. Pomelli, J. W. Ochterski, P. Y. Ayala, K. Morokuma, G. A. Voth, P. Salvador, J. J. Dannenberg, V. G. Zakrzewski, S. Dapprich, A. D. Daniels, M. C. Strain, O. Farkas, D. K. Malick, A. D. Rabuck, K. Raghavachari, J. B. Foresman, J. V. Ortiz, Q. Cui, A. G. Baboul, S. Clifford, J. Cioslowski, B. B. Stefanov, G. Liu, A. Liashenko, P. Piskorz, I. Komaromi, R. L. Martin, D. J. Fox, T. Keith, M. A. Al-Laham, C. Y. Peng, A. Nanayakkara, M. Challacombe, P. M. W. Gill, B. Johnson, W. Chen, M. W. Wong, C. Gonzalez and J. A. Pople, Gaussian 03 (Revision E.01), Gaussian, Inc., Wallingford CT, 2004.

$38 \mathrm{~T}$. Lu, sobMECP program, http://sobereva.com/286, accessed, 31 March 2017.
39 J. Harvey, M. Aschi, H. Schwarz and W. Koch, Theor. Chem. Acc., 1998, 99, 95-99.

40 A. D. Becke and K. E. Edgecombe, J. Chem. Phys., 1990, 92, 5397-5403.

41 A. Savin, R. Nesper, S. Wengert and T. R. Fassler, Angew. Chem., Int. Ed. Engl., 1997, 36, 1808-1832.

42 R. F. W. Bader, Atoms in Molecules: A quantum theory, Clarendon, Oxford, 1990.

43 I. Mayer, Chem. Phys. Lett., 1983, 97, 270-274.

44 T. Lu and F. Chen, J. Comput. Chem., 2012, 33, 580-592.

45 A. Fernandez-Ramos, B. A. Ellingson, B. C. Garrett and D. G. Truhlar, Rev. Comput. Chem., 2007, 23, 125-232.

46 E. Wigner, Z. J. Phys. Chem. B, 1932, 19, 203-216.

47 C. Eckart, Phys. Rev., 1930, 35, 1303-1309.

48 S. Canneaux, F. Bohr and E. Henon, J. Comput. Chem., 2014, 35, 82-93.

49 D. W. Green and G. T. Reedy, J. Chem. Phys., 1978, 69, 544551.

50 P. Li, W. Niu, T. Gao and H. Y. Wang, Int. J. Quantum Chem., 2014, 114, 760-768.

51 P. Li, W. Niu, T. Gao and H. Y. Wang, J. Mol. Model., 2014, 20, 2466.

52 P. Li, W. Niu and T. Gao, J. Radioanal. Nucl. Chem., 2015, 304, 489-499.

53 P. Li, W. Niu and T. Gao, RSC Adv., 2017, 7, 4291-4296.

54 D. Cremer and E. Kraka, Angew. Chem., Int. Ed. Engl., 1984, 23, 627-628; Angew. Chem., 1984, 96, 612-614.

55 R. F. W. Bader, T. S. See, D. Cremer and E. Kraka, J. Am. Chem. Soc., 1983, 105, 5061-5068.

56 C. S. López, O. N. Faza, F. P. Cossío, D. M. York and A. R. de Lera, Chem.-Eur. J., 2005, 11, 1734-1738. 